\title{
INTERACCION DE DOS HONGOS TOXICOGENICOS CON UNA CEPA DE STREPTOMYCES SOBRE EL DESARROLLO DE PLANTAS DE TRIGO
}

\author{
Cecilia L. Fulgueira*, Alfredo L. Borghi* \\ Marta A. Gattuso*, Susana J. Gattuso** \\ Blanca J.C. de Bracalenti* \\ *Centro de Referencia de Micología (CEREMIC) \\ **Cátedra de Botánica. \\ Facultad de Ciencias Bioquímicas y Farmaceúticas. \\ Universidad Nacional de Rosario. Suipacha 531 \\ 2000 Rosario-República Argentina.
}

Palabras clave: Antagonismos, Streptomyces, Aspergillus parasiticus, Fusarium tricinctum, plantas de trigo. Key words: Antagonism, Streptomyces, Aspergillus parasiticus, Fusarium tricinctum, wheat seeds.

RESUMEN

Entre los microorganismos antagonistas de los suelos donde se cultivan cereales se hallan Streptomyces capaces de producir sustancias inhibidoras que pueden afectar la viabilidad y capacidad de diseminación de distintas especies de Aspergillus y Fusarium y su capacidad para producir aflatoxinas y trichotecenos.

El objetivo del presente estudio fue evaluar el efecto de la interacción entre hongos toxicogénicos (Aspergillus parasiticus y Fusarium tricinctum NRRL 3299) y Streptomyces sp.antagónicos del crecimiento de tales hongos sabre el desarrollo de plantas de trigo.

Se realizaron las siguientes actividades: a) inoculación de semillas de trigo, con el Streptomyces inhibidor, b)estudio del poder germinativo de las semillas de rigo,c) cultivo en cámara invernáculo de semillas inoculadas y sin inocular sembradas en tierras con y sin los hongos toxicogénicos, d) comprobación de la invasividad - ataque de los hongos mediante el rociado de espigas de plantas provenientes de suelos infectados con una suspensión de conidios de los hongos infectantes,e) determinación de las variaciones en las características botánicas de las plantas de trigo.

Se pudo concluir que: 1) la presencia de hongos toxicogénicos no alteró el poder germinativo de las semiLlas de trigo, 2) el desarrollo vegetal, número y peso promedio de los granos de las plantas provenientes de suelos infectados con los hongos toxicogénicos fué significativamente mayor al de las plantas crecidas en tierra estéril, 3) el estudio anatòmico de las plantas no puso en evidencia invasión o ataque por parte de los hongos.

\section{SUMMARY}

[Interaction of two toxigenic fungi with a strain of Streptomyces on the development of wheat seeds.]

Streptomyces capable of producing inhibitory substances that may affect the viability and disseminating different species of Aspergillus and Fusarium and their capacity to produce aflatoxins and trichothecenes, are found among the antagonist microorganism of the soils where cereals are grown.

The object of this works was to evaluate the effect of the interaction among toxicogenic fungi (Aspergillus parasiticus NRRL 2999 and Fusarium tricinctum NRRL 3299) and antagonic Streptomyces sp on the development of wheat plants.

The following activities were carried out: a) inoculation of wheat seeds with inhibitor Streptomyces, b) analysis of the germinative power of the inoculated seeds, c) culture in hot-house and culture of non-inoculated seeds in lands with and without toxigenic fungi, d) spray of spikes of the infected fungi, $e$ ) determination of the variances in the botanical features of wheat plants.

It was concluded that: 1) the presence of toxigenic fungi did not alter the germinative power of seeds of wheat; 2)thevegetal development, number and weight, of the average grains of the plants from infected soils was significantly greater than the development of the plants grown in non-fertile soil; 3) the anatomic study of the plants did not shown evidence of invasion of fungi. 


\section{INTRODUCCION}

El problema de la preservación de granos de cereales yoleaginosas al ataque de hongos productores de toxinas altamente peligrosas para la salud humana y animal, ha sido y es motivo de investigaciones importantes (1).

En los granos en desarrollo y durante el almacenamiento post-cosecha, los hongos son expuestos a interacciones complejas con la especie hospedera. Su condición fisiológica y su crecimiento dependen de varios factores como la presencia de otros microorganismos, de los biocidas aplicados en distintas etapas de desarrollo de la semilla o de los preservativos empleados durante el almacenamiento (2).

La competición entre organismos, es uno de los factores más importantes que determinan la densidad de poblaciones en la naturaleza.

Los Streptomyces por su amplia distibución, tolerancia térmica, alto potencial metabólico, probada capacidad $\infty$ mo antagonistas fúngicos, su buen crecimiento filamentoso en los suelos y la producción de antibioti$c o s$, pueden participar activamente en el establecimiento del equilibrio microbiológico del suelo y constituirse-en un factor que afecta la viabilidad y capacidad de ciertos hongos como el Aspergillus flavus y Aspergillus parasiticus y distintas especies de Fusarium $(3,4)$.

En una etapa previa, se seleccionó una cepa de Streptomyces sp. entre todas aquellas aisladas de suelo que produjeron inhibición del Aspergillus parasiticus NRRL 2999 y del Fusarium tricinctum NRRL 3299. Probandose "in vitro" su poder antagonista sobre la germinación y el crecimiento de los mencionados hongos y determinandose si tal acción era debida a antagonismo o competencia. Se demostró en los estudios realizados que, cuando el Streptomyces $s p$. creció conjuntamente con el $A$. parasiticus y con el $F$. tricinctum alteró la germinación y el crecimiento de estos hongos, siendo la etapa de desarrollo de este, determinante en sus efectos y atribuibles a la producción de metabolitos inhibidores por parte del Streptomyces, que actuarían sobre la germinación de los conidios más que a una competición por el sustrato $(5,6)$.

El problema en salud vegetal, comienza con la germinación de la semilla. Si ésta se mantiene bien nutrida y provista de carbohidratos, la germinación será rápida y la microvida a su alrededor compuesta por bacterias y varios hongos, entre ellos, Aspergillus y Penicillium, la beneficiará acelerando su germinación. Pero cuando sucede lo contrario, los microorganismos la atacarán, actuando como descomponedores, lo que imposibilitará su germinación a futuro (7).
Por ésto se decidió adicionar a los estudios "in vitro" citados anteriormente, pruebas en el mismo suelo donde se cultivan cereales.

Para ello se llevaron a cabo las siguientes actividades:

1.- Inoculación experimental de semillas de trigo con el Streptomyces inhibidor.

2.-Estudio del poder germinativo de dichas semillas inoculadas.

3.-Experiencias en cámara-invernáculo de cultivo de semillas de trigo inoculadas y sin inocular, en tierras con y sin la presencia de los hongos toxicogénicos, para determinar la efectividad del Streptomyces (presente naturalmente en el mismo suelo donde se desarrollan los cereales) como agente inhibidor contra los hongos en condiciones de campo.

\section{MATERIALES Y METODO}

1) Preparación del homogenizado del antagonista. - Para usar en inoculación de superficie, la cepa Streptomyces sp. C/33-6 aislado de suelo, fué cultivado en Agar Papa Dextrosa en placas de Petri a $28^{\circ} \mathrm{C}$ durante 7 días. Luego el contenido de todas las placas fué raspado y colocado en un agitador Wering junto con $20 \mathrm{ml}$ de agua por placa de Petri y agitado por 30 segundos. Finalmente $5 \mathrm{ml}$. de solución de goma arábiga $(0,2 \mathrm{~g} / \mathrm{ml})$ fueron agregados a este homogenizado. Parte de las semillas de trigo fueron sumergidas en él para inocularlas con el Streptomyces antagonista (8).

2) Preparación del inóculo-stock del patógeno. Para infectar el suelo de las macetas con los hongos toxicogénicos, se utilizó tierra especial (compost). Esta fue esterilizada previamente 4 horas a $121^{\circ} \mathrm{C}$ en autoclave, en 4 bolsas de papel conteniendo aproximadamente $500 \mathrm{~g}$. cada una. Después de enfríado, el contenido fue transferido a sendas bolsas de polietileno.

Por otro lado, los cultivos agitados de $A$. parasiticus NRRL 2999 y $F$. tricinctum NRRL 3299 desarrollados en Caldo Papa Dextrosa (CPD) a $28^{\circ} \mathrm{C}$ por 7 días, fueron diluídos con 5 partes de CPD. Veinte $\mathrm{ml}$ de estos cultivos diluídos fueron colocados en cada bolsa de polietileno (dos para cada hongo). Las bolsas fueron agitadas con la mano para humedecer e inocular todo el contenido y finalmente fueron colocadas en estufa a $28^{\circ} \mathrm{C}$. Todos los días las bolsas fueron abiertas y agitadas muchas veces para aireación y luego cerradas de nuevo.

Después de 21 días de incubación el contenido de las bolsas infectadas (inóculo-siock) estuvo listo para la inoculación en la tierra de las macetas. 
3) Estudio del poder germinativo de las semillas de trigo.- Se utilizaron semillas de trigo variedad Marco Juárez INTA, a las que se les probó su poder germinativo en las siguientes condiciones:a)En placas de Petri con discos de papel de filtro humedecidos, se colocaron 50 semillas de trigo por caja y se incubaron 3 días a $28^{\circ}$ $C$, al cabo de los cuales se determino el porcentaje que emitió radícula; b)Se determinó de la misma manera el poder germinativo de las semillas de trigo inoculadas con Streptomyces; c) Se estudió también el poder germinativo de las semillas inoculadas con Streptomyces, pero en presencia de $A$.. parasicicus NRRL 2999. Para ello se prepararon placas de APD sobre las que se sembró una suspensión de conidios del Aspergillus y sobre ellas se depositaron las semillas de trigo inoculadas con Streptomyces; d) Se determinó también el poder germinativo de semillas de trigo inoculadas con Streptomyces, colocadas sobre placas de APD en las que se había sembrado previamente una suspension de conidios de $F$. tricinctum NRRL 3299.

4) Siembra de las semillas de trigo.- La siembra se efectuó en macetas, a razón de 10 semillas en cada una. A cada maceta, que contenia una base de tierra natural suplementada con una capa de tierra estéril, le correspondió un tratamiento distinto de acuerdo a la Tabla $\mathrm{N}^{\circ} 1$.

Tabla $N^{\circ} 1$

Esquema de siembra de las semillas de trigo en las, distintas macetas.

\begin{tabular}{|lll|}
\hline & \multicolumn{1}{c|}{$\begin{array}{c}\text { Semillas } \\
\text { sin inocular }\end{array}$} & $\begin{array}{c}\text { Semillas } \\
\text { inoculadas }\end{array}$ \\
\hline $\begin{array}{l}\text { Tierra } \\
\text { Esteril }\end{array}$ & Maceta $N^{\circ} 1$ & Maceta $N^{\circ} 2$ \\
\hline $\begin{array}{l}\text { Tierra } \\
\text { Esteril } \\
+ \text { Fusarium }\end{array}$ & Maceta $N^{\circ} 3$ & Maceta $N^{\circ} 4$ \\
\hline $\begin{array}{l}\text { Tierra } \\
\text { Esteril } \\
+ \text { Aspergillus }\end{array}$ & Maceta $N^{\circ} 5$ & Maceta $N^{\circ} 6$ \\
\hline
\end{tabular}

Todas las macetas fueron colocadas en una cámarainvernáculo durante 120 días, mantenidas a una temperatura entre $25-28^{\circ} \mathrm{C}$, a una humedad relativa entre $60-80 \%$ y con un fotoperíodo de 14 horas de luz y 10 horas de oscuridad.

A los 30 días de la siembra se retiró una plántula de cada maceta y se procedió a su fijación con formolalcohol-ácido acético (F.A.A.), incluyendo en parafina, cortando en forma seriada $(9,10)$ los siguientes organos: raíz embrional, raíz adventicia, mesocótilo, tallo con coleóptile, nomófilos y nudo cotiledoneal .Todo ésto coloreado con Safranina-Fast Green (11).

A los 64 días se rociaron tres espigas de la maceta No 3 con una suspensión que contenía $6,2 \times 10^{5}$ conidios de F. tricinctum NRRL $3299 / \mathrm{ml}$. y tres espigas de la maceta $N^{\circ} 5$ con una suspensión de $7,5 \times 10^{5}$ conidios de $A$. parasiticus NRRL $2999 / \mathrm{ml}$.

A los 77 días se rociaron de manera similar tres espigas de la maceta $\mathrm{N}^{\circ} 4$ con $\boldsymbol{F}$. tricinctum y tres espigas de la maceta $\mathrm{N}^{\circ} 6$ con $A$. parasiticus.

A los 7, 15 y 21 días de efectuado el rociado, se seleccionaron cariopsis, se cortaron por el surco longitudinal $(8,9)$, se fijaron con F.A.A., se incluyeron en parafina, se cortaron longitudinalmente y colorearon con Safranina-Fast Green.

Los granos de almidón fueron analizados con luz polarizada.

Al cabo de los cuatro meses de incubación, se retiró las macetas de la cámara, se separó la porción aérea de cada planta y se determinó:

a) Peso seco de la porción aérea colocando las plantas en una estufa a $60^{\circ} \mathrm{C}$ durante 48 horas hasta determinación de peso constante.

b) Número de espigas producidas.

c) Número y peso seco de los granos obtenidos a partir de tales plantas.

Una vezseccionada la porción aérea se extrajo las raíces de las plantas, lavandolas con agua destilada, se sembró las suspensiones así obtenidas en placas de APD y se incubaron a $28^{\circ} \mathrm{C}$ durante 7 días para determinar la presencia o no de los hongos inoculados.

Se determinaron además los datos fenológicos correspondientes al tiempo de emergenciay espigazón de las distintas macetas.

\section{RESULTADOS}

El estudio del poder germinativo de las semillas de trigo arrojó los siguientes resultados: en los casos a) yb) el $99 \%$ de las semillas emitieron la radícula y en los casos c) y d) se observó germinación en el $98 \%$ de las semillas.Los resultados obtenidos en la determinacion de los pesos secos de la porción aérea de cada planta se presentan en la tabla $\mathrm{N}^{\circ} 2$. Se efectuó el análisis estadístico de los resultados por comparación de los promedios de a dos, utilizando la variable t-Student y considerando la estimación de la varianza de error a partir de la combinación de las varianzas de los 6 grupos (en base a la igualdad estadística de varianza por el método de Battlet).

La comparación de los promedios de los pesos 
secos y su significación estadística se muestran en la Tabla $N^{\circ} 2$.

Tabla No2

Comparación entre los promedios por maceta de los pesos secos de la porción aérea de las plantas de trigo y su significación estadística

\begin{tabular}{|ccr|}
\hline $\begin{array}{c}\text { Macetas } \\
\mathrm{N}^{\circ}\end{array}$ & $\begin{array}{c}\text { Pesos Secos } \\
\text { Promedios } \\
(\mathrm{g})\end{array}$ & $\begin{array}{r}\text { Significación } \\
\text { Estadística }\end{array}$ \\
\hline $2-1$ & $0,6433-0.6076$ & No significativa \\
$3-1$ & $1,8187-0,6076$ & Significativa \\
$4-2$ & $2,0784-0,6433$ & Significativa \\
$4-3$ & $2,0784-1,8187$ & No significativa \\
$5-1$ & $1,6164-0,6076$ & Significativa \\
$5-3$ & $1,6164-1,8187$ & No significativa \\
$6-2$ & $1,5014-0,6433$ & Significativa \\
$4-6$ & $2,0784-1,5014$ & No significativa \\
$5-6$ & $1,6164-1,5014$ & No significativa \\
\hline
\end{tabular}

El número de espigas producidas en promedio por planta y el número y peso seco promedio de los granos obtenidos a partir de tales espigas correspondientes a los distintos tratamientos se presentan en la Tabla No3.

\section{Tabla $\mathrm{N}^{\circ} 3$}

Número promedio de espigas producidas por planta, $y$ número y peso seco promedios de los granos obtenidos a partir de tales espigas, correspondientes a los distintos tratamientos

\begin{tabular}{|ccrr|}
\hline $\begin{array}{c}\text { Maceta } \\
\mathbf{N}^{\circ}\end{array}$ & $\begin{array}{c}\mathbf{N}^{\circ} \\
\text { de Espigas } \\
\text { Promedio }\end{array}$ & $\begin{array}{r}\mathbf{N}^{\circ} \\
\text { de Granos } \\
\text { Promedio }\end{array}$ & $\begin{array}{r}\text { Peso } \\
\text { de Granos } \\
\text { Promedio }\end{array}$ \\
\hline & 1,333 & 1,167 & 0,0288 \\
1 & 1,4 & -- & -- \\
$3^{*}$ & 2,555 & 8,942 & 0,3194 \\
3 & 2,555 & 9,368 & 0,2789 \\
$4^{*}$ & 2,0 & 6,667 & 0,2533 \\
4 & 2,0 & 11,231 & 0,3444 \\
$5^{* *}$ & 2,889 & -- & - \\
5 & 2,889 & 6,861 & 0,1951 \\
$6^{* *}$ & 1.555 & 20,249 & 0,7344 \\
6 & 1,555 & 7,775 & 0,2575 \\
Plantas rociadas con una suspension de conidios del F. tricinctum \\
*) o del A. parasiticus (**)
\end{tabular}

El estudio morfológico y anatómico de las plántulas reveló las siguientes particularidades:

Maceta $\mathrm{N}^{\circ}$ 2: mesocótile largo.

Macetas $N^{\circ} 3$ y 4 : mesocótile corto o nulo y raíz adventicia gruesa.

Maceta $\mathrm{N}^{\circ}$ 5: plántula pequeña, sin raíces adventicias y mesocótile muy largo.

Maceta $N^{\circ}$ 6: mesocótile corto y raíces adventicias originadas del nudo basal y del nudo del coleóptile.

El estudio anatómico de los diferentes órganos no puso en evidencia invasion o ataque por parte de los hongos.

Morfologicamente los cariopsis rociados con conidios fúngicos mostraron diferencias con respecto al material sin rociar, pues resultaron granos de mayor volumen (Fig. 1).

El estudio de los cariopsis testigos mostró una anatomía normal'(Fig. 2-A).

Los cariopsis rociados con la suspensión de conidios de Aspergillus a los 7 días de tratamiento mostraron en la capa de aleurona (a) del embrión un precipitado fino, oscuro y poco denso (p) el que también se encontró presente en escasa cantidad a nivel del escutelo (e) (Fig. 2-B). A los 15 días se intensificó este precipitado, aumentó su dispersión y se hizo visible en las regiones apicales caulina (c) y radical (r) (Fig. 2-C). A los 21 días el fenómeno fué más intenso (Fig. 2-D)). El endospermia amiláceo (s) y el pericarpio (m) no se vieron afectados.

Los cariopsis rociados con Fusarium mostraron a los 7 días del tratamiento en la capa de aleuronas (a) del embrión un precipitado grueso y oscuro que también se encontró en forma abundante en el escutelo (e). La región del endosperma amiláceo (s) adosada a la capa aleuronífera presentó algunas células con un contenido no estructurado (x) que se coloreó de rojo con la Safranina (Fig. 2-E). A los 15 y 21 días los procesos descritos se intensificaron ((Fig. 2F-G). Con este tratamiento el pericarpio no fué afectado.

En los cultivos obtenidos a partir de la tierra extraída de la rizosfera de las macetas $N^{\circ} 5$ y 6 , se aisló predominantemente $A$. parasiticus NRRL 2999 mientras que en las macetas $\mathrm{N}^{\circ} 3$ y $4, F$. tricinctum fue recuperado, pero junto con otras cepas fúngicas ambientales.

Los datos fenológicos correspondientes a las semillas de trigo en las condiciones del experimento, revelaron que: transcurrieron 4 días desde la siembra a la emergencia en todos los casos, además en las macetas infectadas la espigazón comenzó a los 49 días después de la emergencia mientras que en las macetas sin infectar ésta se retras 6 hasta los 64 días.

\section{DISCUSION}

A través del análisis de los datos experimentales obtenidos podemos concluir que: 

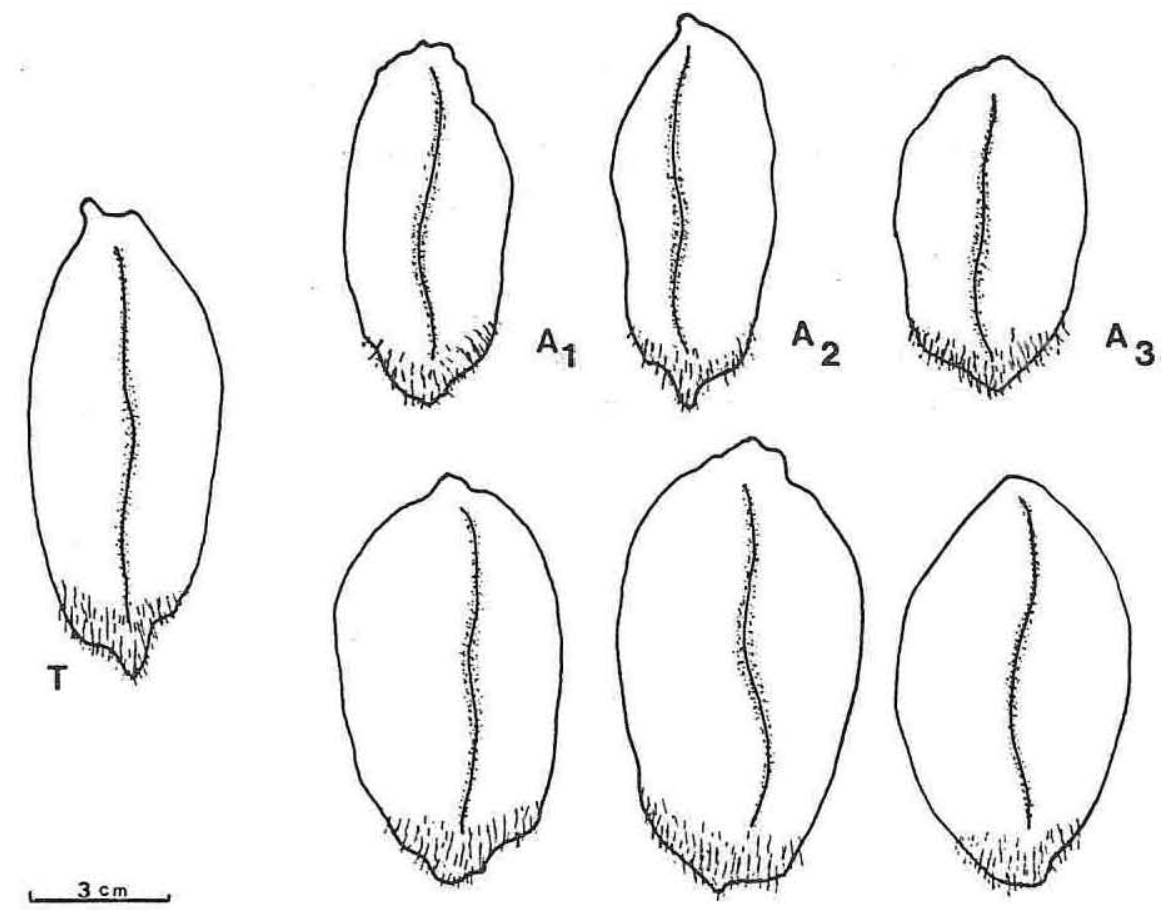

$F_{1}$

$F_{2}$

$F_{3}$

Fig. 1: Variaciones morfológicas en Triticum sativum (T) producidas por el rociado de sus espigas con conidios de $A$. parasiticus NRRL 2999 (A1, A2, A3) o de F tricinctum NRRL 3299 (F1, F2, F3).

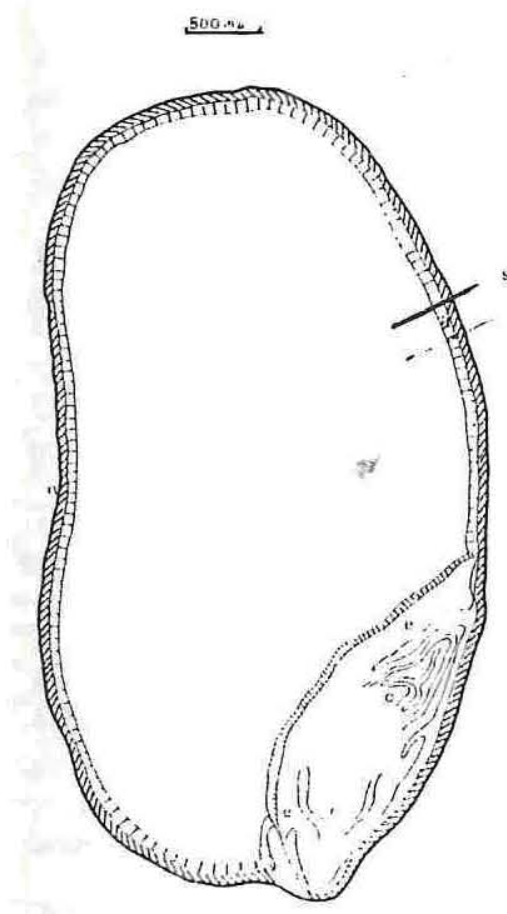

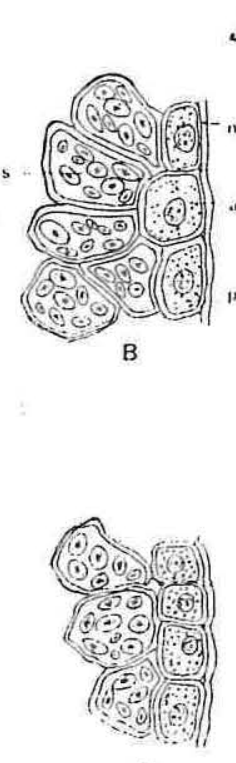

C

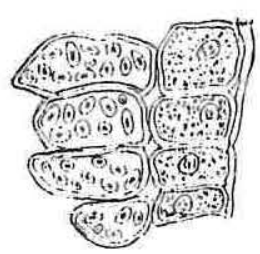

D

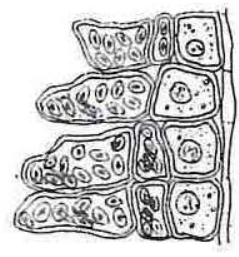

E

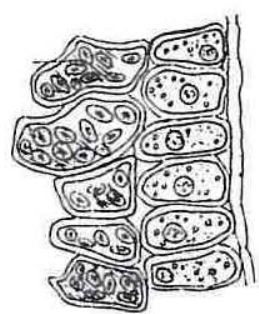

F

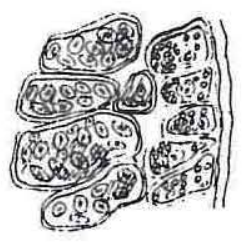

G

A

Fig. 2: Variaciones histologicas observadas en cortes longitudinales de cariopsis de Triticum sativum (A) producidas por el rociado de sus espigas con conidios de A. parasiticus NRRL 2999 (B, C, D) o de F. tricinstum NRRL 3299 (E, F, G). 
*El desarrollo vegetal de las plántulas provenientes de semillas sembradas en suelos infectados con A.parasiticus ocon $F$, tricinctum fué significativamente mayor al de las plantas crecidas en tierra estéril, no existiendo ninguna diferencia atribuible a un hongo en particular o a la inoculación de las semillas con Streptomyces sp.

* Observando los datos de la Tabla No3, podemos afirmar que aunque no se presentaron diferencias significativas en el número de espigas promedio por planta en los diferentes tratamientos, el número y el peso delos granos promedio fuésuperior en las plantas cultiviadas en tierras infectadas.

Estos efectos podrían atribuirse al rol beneficioso desarrollado por los hongos presentes en la rizosfera. Actualmente se sabe que la rizosfera vegetal está densamente poblada por hongos y bacterias, aprovechando las excresiones radiculares que varían desde azúcares y aminoácidos, ácidos orgánicos y enzimas, vitaminas y sustancias de crecimiento e inhibición $(12,13,14,15)$. Existe así un efecto altamente selectivo sobre los microorganismos en general y los hongos en particular. Los hongos, a su vez movilizan nutrientes minerales hacia las plantas, aumentan la posibilidad de retirar agua del suelo, fijan nitrógeno, defienden la rizosfera por medio de antibióticos $(17,18)$ y pueden en algunos casos incrementar la producción de hormonas de crecimiento vegetal (auxinas) $(19,20)$.

*El efecto de rociado de las espigas con Aspergillus dependio de la inoculación o no con Streptomyces de las semillas sembradas en las macetas, mientras que el rociado con Fusarium no afectó la producción de granos en las plantas inoculadas o no con Streptomyces. Además en ninguno de los cariopsis se observó la presencia de hifas ni conidios fúngicos lo que indicaría que el hongo no penetra en las semillas, aunque las modificaciones anatómicas registradas en la Figura 2 pondrían de manifiesto talvez un posible efecto tóxico producido por los hongos toxicogénicos.

*Teniendo en cuenta que no se presentó ataque o invasión por parte de los hongos a las plantas de trigo, no pudo determinarse si Streptomyces sp. C/33-6 ejerció o no una acción protectora sobre tales plantas.

\section{REFERENCIAS}

1.- Smith,J.E. \& Ross, M.C.(1985). "Mycotoxins, formation, analysis and significance". John Wiley Sons Ed. Geat Britain.

2.-Moss, M.O. \& Frank, J.M. (1985). "Trichotecens and other mycotoxins". John Wiley and Sons Ed. Great Britain.

3.-Goodfellow, M. \& Williams,S.S. (1983). "Ecology of Actinomycetes". Ann. Rev. Microbiol. 37: 189-216.

4.-Gupta, R.C. \& Tandon, R.N. (1977). "Growth inhibition of fungi by volatiles from Streptomyces". Trans. Brit. Mycol. Soc. 68: $438-439$.

5. Borghi, A.L.; Fulgueira, C.L. \& Bracalenti, B.J.C. de. (1988). "Inhibicion de Fusarium graminearum por una cepa de Streptomyces sp.". Bol, Micol. 4: 237-242.

6.-Fulgueira,C.L.; Borghi,A.L. \& Bracalenti,B.J.C. de.(1989). "Inhibición de Aspergillus parasiticusNRRL 2999 por una cepa de Streptomyces sp..". Rev. Microbiol. 20:215-222.

7.-Tomaselli, L. \& Florenzani, G. (1971). "Heterotrophy and nitrogen fixation in several blue green algae from soil". Zblt. Bakteriol. Paras. Infeckt. Hig. 2 Abt. 126: 420-424.

8.-Turham, G. (1981). "A new race of Streptomyces ochraceisclerolicus in the biological control of some soilborne plant patho gens II. In vivo studies on the possibilities of using $C / 2-9$ against some important diseases". J: of Plant Diseases and Protection 88 : 422-434.

9.-Esau, K. (1982). "Anatomía de las plantas con semillas". Hemisferio Sur Ed. República Argentina.

10.-Fhan, A. (1985). "Anatomía vegetal". Editorial Pirámide. España.
11.- Strimatter, C. (1979). "Modificación de una técnica de coloración de Safranina-Fast Green". Bol. Soc. Arg. Bot. 18 : 121-122.

12.-Daft, M. J. \& Nicholson, T.H. (1969). "The effect of endogen micorrhiza on plant growth". New Phytolog. 68 : 953-963.

13.-Darbyshire,J.F. (1972). Nitrogen fixation by Azotobacter chrococcum in the presence of Colpodia steinii I. The influence of temperature". Soil Biol. Biochem. 4 : 359-369.

14.-Andal, R; Bhuveneswari,K. \& Subra-Rav, N.S. (1965). "Root exudation of paddy". Nature 178: 1063-1069.

15.-Richards, B.N. (1965). "Mycorriza development of lobolly pine seedlings in relation to soil reaction and the supply of nitrate". Plant \& Soil 22 : 187-199.

16.-Timonin, M.J. (1980). "The interaction of higher plants and soil microorganisms I: Microbial population of rhizosphere of seedlings of certain cultivated plants". Canad. J. Res. 18: $307-$ 317.

17.-Lockhead, A. G.; Timonin, M. J. \& West, P.M. (1958). " Soil bacteria and growth promoting substances". Bact. Rew: 22 : 145-153.

18.-Primavesi, A. (1984). "Manejo ecológico del suelo". El Ateneo. Pedro García, S.A. Ed. Rep. Arg.

19.-Devlin, R. M. (1979). "Fisiología vegetal". Ediciones Omega S.A. España.

20.-Thimann, K.V.(1985). "On the plant growth hormone produced by Rhizopus suinus". J. Biol. Chem. 109: 279-281. 